https://helda.helsinki.fi

\title{
Deuterium retention on the tungsten-coated divertor tiles of JET ITER-like wall in 2015-2016 campaign
}

\section{JET Contributors}

2019-09

JET Contributors, Lahtinen , A , Likonen , J , Koivuranta , S , Alves , E , Baron-Wiechec , A , Catarino , N , Coad , J P , Heinola , K , Räisänen , J \& Widdowson , A 2019 , ' Deuterium retention on the tungsten-coated divertor tiles of JET ITER-like wall in 2015-2016 campaign ' , Fusion Engineering and Design, vol. 146 , pp. 1979-1982 . https://doi.org/10.1016/j.fusengdes.2019.03.081

http://hdl.handle.net/10138/334439

https://doi.org/10.1016/j.fusengdes.2019.03.081

cc_by_nc_nd

acceptedVersion

Downloaded from Helda, University of Helsinki institutional repository.

This is an electronic reprint of the original article.

This reprint may differ from the original in pagination and typographic detail.

Please cite the original version. 


\title{
Deuterium retention on the tungsten-coated divertor tiles of JET ITER-Like Wall in 2015-2016 campaign
}

\author{
A. Lahtinen ${ }^{1 *}$, J. Likonen ${ }^{2}$, S. Koivuranta ${ }^{2}$, E. Alves ${ }^{3}$, A. Baron-Wiechec ${ }^{4}$, N. Catarino ${ }^{3}$, J.P. Coad ${ }^{4}$, \\ K. Heinola ${ }^{1}$, J. Räisänen ${ }^{1}$, A. Widdowson ${ }^{4}$ and JET Contributors ${ }^{* *}$ \\ ${ }^{1}$ Department of Physics, University of Helsinki, P.O. Box 43, 00014 University of Helsinki, Finland \\ ${ }^{2}$ VTT Technical Research Centre of Finland Ltd., P.O. Box 1000, 02044 VTT, Finland \\ ${ }^{3}$ Instituto Superior Tècnico, Universidade de Lisboa, 1049-001 Lisboa, Portugal \\ ${ }^{4} C C F E$, Culham Science Centre, Abingdon, OX14 3DB, UK \\ ${ }^{* *}$ See the author list of "X. Litaudon et al 2017 Nucl. Fusion 57 102001"
}

\begin{abstract}
Tungsten-coated divertor tiles exposed during the third JET ITER-Like Wall (ILW) campaign in 2015-2016 (ILW3) were studied with Secondary Ion Mass Spectrometry (SIMS). ILW-3 campaign contained more high-power plasma discharges and longer plasma time than the earlier ILW campaigns. Measurements showed increased beryllium (Be) deposition on the upper inner divertor, whereas on the outer divertor, Be deposition was lower than during the second campaign in 2013-2014 (ILW-2). Increased intensities of nickel, molybdenum and tungsten were observed at the surface layer of the inner divertor Be dominated deposits. These layers are probably formed during the high-power plasma discharge phase near the end of the ILW-3 campaign. Compared to the earlier campaigns, D retention on the upper inner divertor was observed to on a similar level than after ILW-2, whereas at the lower inner divertor and most parts of the outer divertor, D retention was lower for ILW-3 than ILW-2. D retention was increased at lower part of outer divertor Tile 7 , where Be deposition was slightly increased. Probable reason for the reduction is the higher surface temperature of the tiles due to higher powers used.
\end{abstract}

Keywords: JET, fuel retention, erosion, deposition

\section{Introduction}

Erosion, deposition, and fuel retention on different plasma-facing components (PFCs) are critical issues for a safe and economic operation of the next-step fusion devices such as ITER and DEMO. To study plasma-wall interactions (PWI) in ITER-like environment, JET tokamak has been operated since 2011 with the ITERlike wall (ILW) [1]: tungsten (W) as a plasma-facing material in the divertor region and beryllium (Be) in the main chamber.

So far there have been three experimental campaigns in 2011-12 (ILW-1), 2013-14 (ILW-2) and 2015-16 (ILW-3). After each campaign, a poloidal set of divertor and main chamber tiles were removed for postmortem analyses. Gas balance analyses during ILW-1 [2] and post-mortem analyses after the ILW-1 and ILW2 [3][4] have shown that the fuel retention is reduced by a factor of 10-20 compared to the earlier JET operation with an all-carbon wall (JET-C). The highest deuterium (D) amounts after ILW-1 and ILW-2 were observed at the Be dominated deposits on the upper part of the inner divertor [3][4].

However, ILW-3 campaign contained longer plasma time and more high-power plasma discharges than ILW-1 and ILW-2 campaigns, which might have affected the deposition and fuel retention during the campaign. To study possible changes, samples from the removed ILW-3 divertor tiles were analysed with different post-mortem analysis methods. This contribution focuses on D retention on W-coated divertor tiles exposed in ILW-3 campaign.

\section{Experimental}

Positions and numbering of the studied divertor tiles and the divertor S-coordinate system are shown in the poloidal cross section of the JET-ILW divertor in Fig. 1. S-coordinate is a poloidal coordinate defined along the divertor surface starting from the upper inner divertor. All studied Tiles $0,1,3,4,6,7$ and 8 were W-coated and exposed only during ILW-3 campaign. Tiles 3, 7 and 8 had a special marker layer coating on a top of carbon fibre composite (CFC) substrate for W erosion/deposition studies: CFC (bulk)/Mo $(3 \mu \mathrm{m}) / \mathrm{W}$ $(12 \mu \mathrm{m}) / \mathrm{Mo}(4 \mu \mathrm{m}) / \mathrm{W}(4 \mu \mathrm{m})$. Tiles $0,1,4$ and 6 had a regular CFC (bulk)/Mo $(3 \mu \mathrm{m}) / \mathrm{W}(10-20 \mu \mathrm{m})$ structure. Bulk W Tile 5 was not analysed.

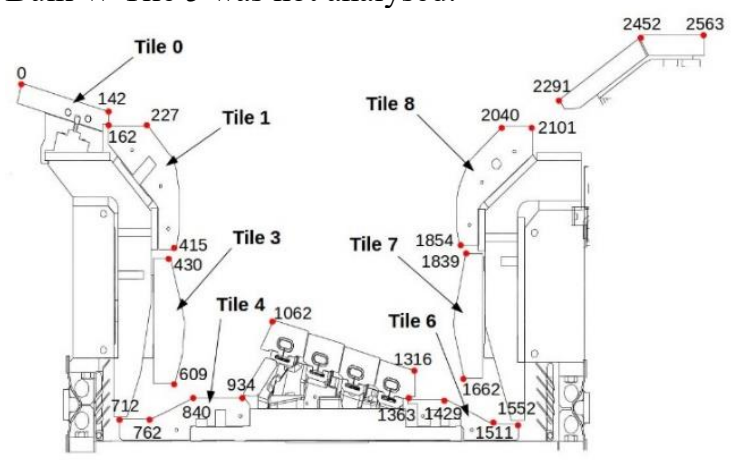

Fig. 1. Poloidal cross section of the JET-ILW divertor with the positions and numbers of the studied tiles and the divertor Scoordinates in $\mathrm{mm}$.

Plasma time (limiter/divertor) for the ILW-1, ILW2 and ILW-3 campaigns were: $19 \mathrm{~h}(6 / 13), 19.4 \mathrm{~h}$ (5.2/14.2), and $23.4 \mathrm{~h}(4.9 / 18.5)$. Total energy inputs for the campaigns were respectively: $150 \mathrm{GJ}, 201 \mathrm{GJ}$, and 245 GJ. Strike point (SP) distributions for the campaigns 


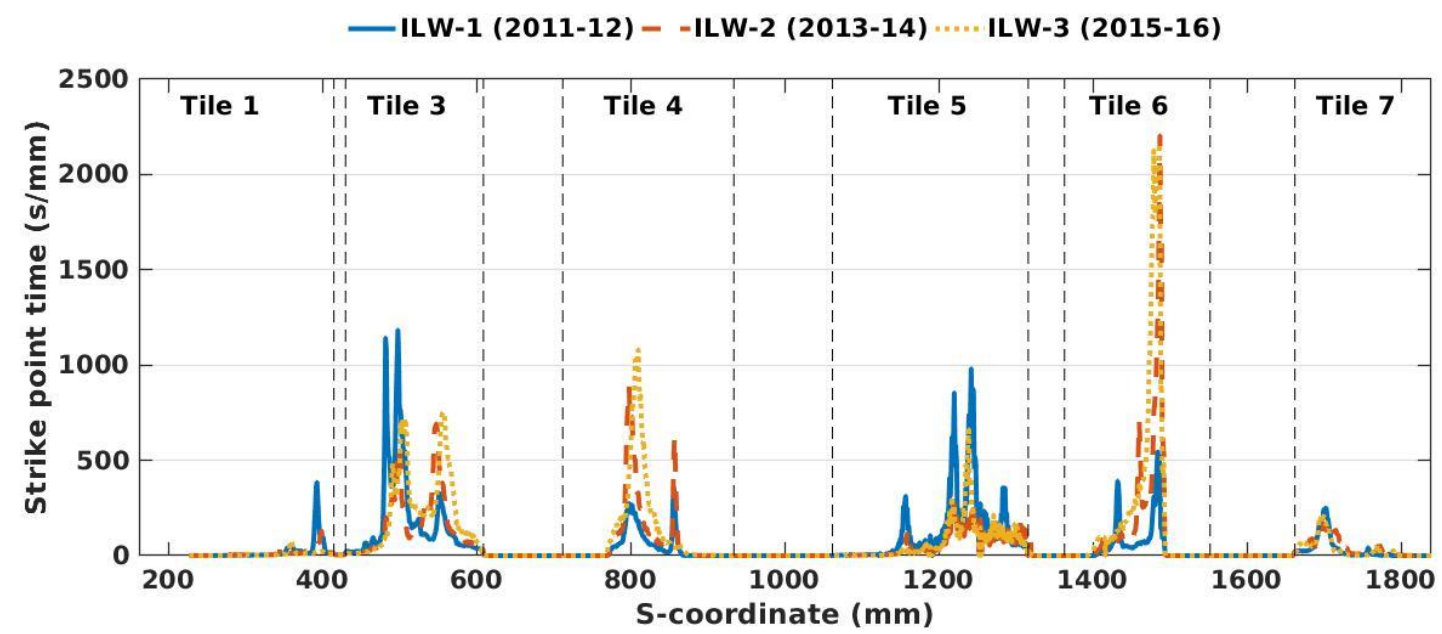

Fig. 2. Strike point distributions of the ILW-1, ILW-2 and ILW-3 campaigns.

are shown in Fig. 2. The ILW-2 and ILW-3 campaigns had quite similar strike point distributions: Inner Strike Point (ISP) on Tiles 3 and 4, and Outer Strike Point (OSP) mainly on Tile 6. However, the plasma time for the ILW-3 campaign was longer and the total input energy higher.

Sample preparation was similar to the earlier studies of the ILW-1 and ILW-2 W-coated divertor tiles [3][5]. Cylindrical samples with a diameter of $\sim 17 \mathrm{~mm}$ were cut from the ILW-3 tiles using a hollow drill. Samples were studied with Secondary Ion Mass Spectrometry (SIMS) using a double focusing magnetic sector instrument VG Ionex IX-70S at VTT technical Research Centre of Finland. A $5 \mathrm{keV} \mathrm{O}_{2}{ }^{+}$primary beam with $500 \mathrm{nA}$ current was raster-scanned over an area of $300 \times 400 \mu^{2}$. A $10 \%$ electronic gate was used to avoid crater wall effects. The intensities of the positive secondary ions at mass to charge ratios $(\mathrm{m} / \mathrm{q})$ of $1(\mathrm{H}), 2$ (D), $9(\mathrm{Be}), 12(\mathrm{C}), 58(\mathrm{Ni}), 98(\mathrm{Mo})$ and $183(\mathrm{~W})$ were measured as a function of time. After each measurement, the depth of the crater was measured with a profilometer. Measurement depth was between $7.5 \mu \mathrm{m}$ and $30 \mu \mathrm{m}$, depending on the thickness of the deposits and depth of D.

To estimate the D amount of the ILW samples, Dimplanted $\mathrm{Be}$, Mo and $\mathrm{W}$ samples were measured to determine Relative Sensitivity Factor (RSF) for D in Be, Mo and W. D contents of the implanted samples were analysed with Heavy Ion Elastic Recoil Detection Analysis (HI-ERDA). D concentrations for the Be, Mo and W layers of the ILW samples were then calculated using the determined RSFs and measured secondary ion intensities. Uncertainties in the quantification of the SIMS measurements, which are mainly related to matrix effects arising from the impurities and mixing of the materials, which might change to yield of secondary ions, are estimated to be about $10 \%$, assuming that the measurement settings are nearly constant during the measurements. More than one measurement was done for each sample and result was calculated as an average.

\section{Results and discussion}

Differences between the campaigns can be seen in the
SIMS measurements. SIMS depth profiles from the plasma-facing surface of Tile 1 are shown in Fig. 3. ILW-2 ended with $\mathrm{H}$ plasma discharges and therefore $\mathrm{H}$ peak was observed at the surface. Depletion of D was observed at the surface of the ILW-2 tiles due to the codeposition of $\mathrm{Be}$ with $\mathrm{H}$ at the deposition regions and isotopic exchange at the implantation regions [5]. ILW3 ended with D plasma discharges and there is D peak at the surface of the all studied ILW-3 tiles. Besides the differences in behaviour of $\mathrm{H}$ and $\mathrm{D}$, another notable difference between the campaigns is the increased intensities of the heavier elements $\mathrm{Ni}$, Mo and $\mathrm{W}$ at the surface of the Be dominated deposits on upper inner divertor Tiles 0 and 1 (Fig. 3.). Ion Beam Analysis (IBA) has also shown increased amounts of $\mathrm{Ni}$ on Tile 1 [6]. Iron $(\mathrm{Fe})$ and chromium $(\mathrm{Cr})$ were not measured with SIMS, but ratios of $\mathrm{Ni}, \mathrm{Fe}$ and $\mathrm{Cr}$ from ion beam measurements suggest that $\mathrm{Ni}, \mathrm{Fe}$ and $\mathrm{Cr}$ on the deposits is from the main chamber Inconel components eroded by the charge exchange neutrals $(\mathrm{CXN})[6]$. W is mainly eroded from the outer divertor tiles, but $\mathrm{CXN}$ erosion of $\mathrm{W}$ coated surfaces of main chamber wall acts also as a W source [6]. After ILW-2, which had a similar strike distribution as ILW-3, clear erosion was observed on tiles 5 and 6 and small erosion on tiles 7 and 8 [7]. Bulk W tile 5 was not analysed, but during ILW-2 deposition and $\mathrm{D}$ retention on tile 5 was very low [7]. Deposited Mo suggests erosion/break-up of the W-coating of some divertor tiles revealing Mo layer underneath. Surface layers of the deposits are probably deposited during the high-power plasma discharge phase near the end of the ILW-3 campaign. Increased intensities of $\mathrm{Ni}, \mathrm{Mo}$ and $\mathrm{W}$ at the surface indicate that during the high-power phase, the erosion of heavier elements and their migration to the inner divertor are higher than during the other plasma operations of the campaign. Fuel retention on and release from the mixed materials are important issues for ITER. Amount of $\mathrm{W}$ in the $\mathrm{Be}-\mathrm{W}$ mixed material is observed to affect the $\mathrm{D}$ retention on the material and $\mathrm{D}$ release behaviour [8].

Thickness of the Be deposits has also changed compared to the SIMS measurements of ILW-2 samples reported in Ref. [5]. For Tile 0, the deposits on a studied 
ILW-3 sample are $\sim 12 \mu \mathrm{m}$ thick, which is only slightly thinner than for the samples close to this location exposed during both ILW-1 and ILW-2 (2011-14). For Tile 1, the thickness of the deposits after ILW-3 ( 2-14 $\mu \mathrm{m})$ is higher compared to the measurements after ILW$2(\sim 1-10 \mu \mathrm{m})$. On the upper part of Tile 3, ILW-3 deposits are thicker $(4-5 \mu \mathrm{m})$ than for 2011-2014 samples $(3-4 \mu \mathrm{m})$. Be deposition extends to lower part of Tile 3 but decreases at the centre and lower part of the tile. There thickness of the deposits is less than $1 \mu \mathrm{m}$, which is lower than for the 2011-2014 samples. On divertor floor Tile 4, Be deposition is low and deposits are less than $0.5 \mu \mathrm{m}$ thick, and significant changes were
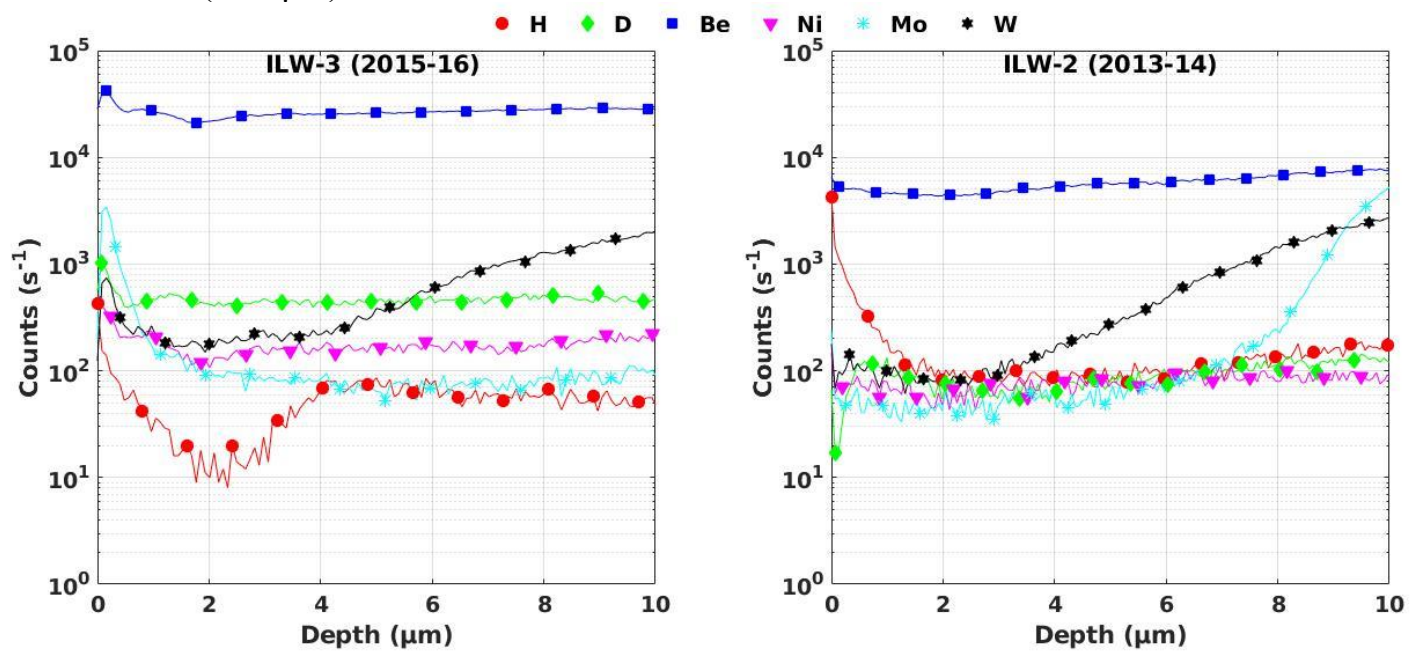

Fig. 3. SIMS depth profiles from plasma-facing surface of Tile 1 after ILW-3 (S=263 mm) and ILW-2 (S=266 mm).

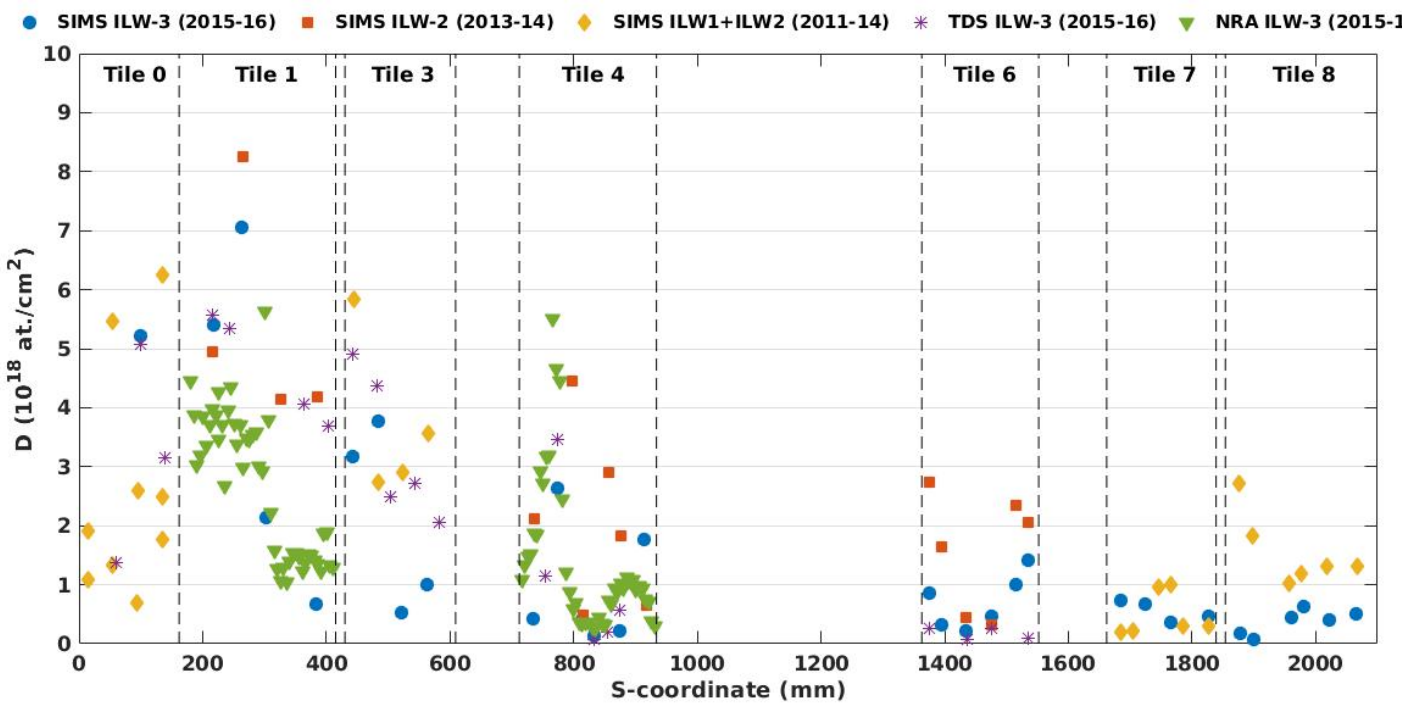

Fig. 4. Poloidal distribution of $\mathrm{D}$ on studied divertor tiles.

not observed between ILW-3 and ILW-2 samples. Overall, thickness of the $\mathrm{Be}$ deposits on the inner divertor during ILW-3 seems to be increased compared to the earlier campaigns, probably due to the longer plasma time and higher powers, which might have caused more erosion on the main chamber Be limiters and migration towards the inner divertor.

For outer divertor floor Tile 6, Be deposition has decreased compared to ILW-2. After ILW-2, about 10 $\mu \mathrm{m}$ thick deposition band was observed close to the main OSP location, whereas after ILW-3, deposits are found from the same location, but the thickness is now only $\sim 3-4 \mu \mathrm{m}$. Although, it is possible that ILW-3 measurements have not been from the thickest spot of the narrow deposition band. For Tile 7, Be deposition is increased on both ends of the tile but the deposits are still very thin, less than $0.5 \mu \mathrm{m}$ thick. For Tile $8, \mathrm{Be}$ deposition is very low and significant changes between the campaigns were not observed.

Earlier studies with micro ion beam analysis $(\mu-$ IBA) methods have shown that $\mathrm{D}$ is non-uniformly distributed at the surfaces of the tiles [9]. More than one SIMS measurement was done for most of the ILW-3 samples and the results were calculated as an average of the measurements. Estimated D amounts for the samples are shown in the Fig. 4. The results show that the main retention area is still on the upper inner divertor and codeposition of $\mathrm{Be}$ and $\mathrm{D}$ dominates the fuel retention on the divertor as observed after the earlier ILW campaigns. For a comparison, SIMS results for 20112014 (Tiles 0, 3, 7 and 8) and 2013-14 (Tiles 1, 4 and 6) [5] are shown in the Fig. 4. Moreover, Thermal Desorption Spectrometry (TDS) and Nuclear Reaction Analysis (NRA) results for the ILW-3 tiles are also 
shown in the Fig. 4. Details of the TDS and NRA measurements can be found from the Ref. [10].

Agreement between the SIMS and NRA results on Tiles 1 and 4 is quite good. SIMS results are higher on the upper part of Tile 1, probably because Be deposits are there thicker $(>10 \mu \mathrm{m})$ than the range of the NRA with $2.3 \mathrm{MeV}^{3} \mathrm{He}$ beam. Agreement between SIMS and TDS is good for Tiles 0 and 4, upper part of Tile 1, and centre of Tile 6. For lower part of Tile 1 and for Tile 3, TDS results are clearly higher than SIMS results, which indicates deeper D retention than 10-20 $\mu \mathrm{m}$ surface layer studied with SIMS. At both ends of Tile 6, SIMS results are higher than TDS results.

D amount on the ILW-3 sample from Tile 0 is on a similar level than the D amount for the 2011-2014 samples. At the upper part of Tile 1, Be deposition was increased but D retention is slightly lower for ILW-3 than ILW-2. At the lower part of the tile, SIMS results for ILW-3 samples are clearly lower than after ILW-2. Possible reason for the lower D retention is higher surface temperature of the tile due to high-power phase at the end of the campaign. Higher exposure temperature leads to lower $\mathrm{D}$ retention for $\mathrm{W}, \mathrm{Be}$ and $\mathrm{Be}-\mathrm{W}$ mixed materials [8]. TDS measurements show higher release temperatures for ILW-3 samples than for ILW-2 [10], which suggest that temperature of tiles during ILW-3 operation has been higher and low energy traps are emptied during the operation. D retention on Tile 3 is lower for ILW-3 than 2011-2014, probably due to the shorter exposure time (only 1 campaign) and higher exposure temperature. For floor Tile 4, D retention is also lower for ILW-3 than after ILW-2, probably due to higher surface temperature of the tile during ILW-3 operation.

For floor Tile 6, the profile of the D retention is quite similar to ILW-2 but D amounts at both ends of the tile are lower. For Tile 7, D retention is increased compared to 2011-14 at lower part of the tile, where Be deposition was increased. Besides the surface D peak, SIMS measurements also showed D peaks at the W-Mo and Mo-W interfaces of the marker coating of Tile 7. Micro beam NRA ( $\mu$-NRA) measurements has also shown deep D trapping at the W-Mo and Mo-W interfaces of the outer divertor tiles [11]. D retention on the tile 8 during 2011-14 had large contributions from these W-Mo and Mo-W interface D peaks [5]. For the ILW-3 samples these interface D peaks are still observed also on the tile 8 , but now they are much smaller than after ILW-2. Therefore, also D retention is clearly lower than for the 2011-2014 samples.

\section{Conclusions}

$\mathrm{D}$ retention on $\mathrm{W}$-coated divertor tiles exposed during ILW-3 campaign were studied with SIMS. Profile of the D retention after the ILW-3 campaign is similar to the earlier campaigns and codeposition of $\mathrm{D}$ with $\mathrm{Be}$ dominates the fuel retention on the divertor as observed earlier. The highest D amounts are found from upper inner divertor Tiles 0 and 1 , where the Be dominated deposits are the thickest, over $10 \mu \mathrm{m}$ thick. Due to the longer plasma time and increased input powers during the campaign, more material on the main chamber was eroded, which is seen as an increased Be deposition on the inner divertor tiles. On Tile 1, the deposits are thicker than after ILW-2, and on parts of Tiles 0 and 3, the thickness of the deposits is on a similar level than after two earlier campaigns ILW-1 and ILW-2 combined (2011-2014).

For Tile 0 and upper part of Tile 1, D amounts after ILW-3 are quite similar than after ILW-2. At lower part of Tile 1, and for Tiles 3, 4, 6 and 8, D amounts are lower for ILW-3 samples than after ILW-2. Probable reasons for the reduction are higher surface temperature of the tiles during ILW-3 operation due to the increased powers and shorter exposure time of Tiles 3 and 8 (only 1 campaign). At lower part of outer divertor Tile 7 where Be deposition increased, D amount is higher for ILW-3 than after 2011-2014.

Notable difference between the campaigns is that the composition of the surface layer of the upper inner divertor deposits is different. On the ILW-3 samples, intensities of the $\mathrm{Ni}, \mathrm{Mo}$ and $\mathrm{W}$ increase at the surface layer, which is probably formed during the high-power plasma discharge phase near the end of the campaign. Surface peaks indicate that the erosion and migration of these elements to the inner divertor is increased during the high-power operation. Changes in the composition of the deposits might affect their properties e.g. the fuel retention and fuel release behaviour.

\section{Acknowledgements}

This work has been carried out within the framework of the EUROfusion Consortium and has received funding from the Euratom research and training programme 2014-2018 under grant agreement No 633053. The views and opinions expressed herein do not necessarily reflect those of the European Commission.

\section{References}

[1] G.F. Matthews et al., Overview of the ITER-like wall project, Physica Scripta T128 (2007) 137-143

[2] S. Brezinsek et al., Fuel retention studies with the ITERLike Wall in JET, Nuclear Fusion 53 (2013) 083023.

[3] K. Heinola et al., Long-term fuel retention in JET ITERlike wall, Physica Scripta T167 (2016) 014075.

[4] K. Heinola et al., Experience on divertor fuel retention after two ITER-Like Wall campaigns, Physica Scripta T170 (2017) 014063.

[5] A. Lahtinen et al., Deuterium retention in the divertor tiles of JET ITER-Like wall, Nuclear Materials and Energy 12 (2017) 655-661.

[6] A. Widdowson et al., Deposition of impurity metals during campaigns with the JET ITER-like Wall, Nuclear Materials and Energy (2018) submitted.

[7] M. Mayer et al., Erosion and deposition in the JET divertor during the second ITER-like wall campaign, Physica Scripta T170 (2017) 014058

[8] I. Jepu et al., Temperature influence on deuterium retention for Be-W mixed thin films prepared by Thermionic Vacuum Arc method exposed to PISCES B plasma, Journal of Nuclear Materials 463 (2015) 983-988.

[9] H. Bergsåker et al., Microscopically nonuniform deposition and deuterium retention in the divertor in JET with ITER-like wall, Journal of Nuclear Materials 463 (2015) 
956-960.

[10] J. Likonen et al., Investigation of deuterium trapping and release in the JET divertor during the third ILW campaign using TDS and TMAP, Nuclear Materials and Energy (2018) submitted.
[11] H. Bergsåker et al., Deep deuterium retention and Be/W mixing at tungsten coated surfaces in the JET divertor, Physica Scripta T167 (2016) 014061 